\begin{tabular}{ll} 
Abstract PTU-37 Table 1 & n (\%) \\
\hline Demographics & 139 \\
\hline Age & $(67 \%)$ \\
$70-79$ & 68 \\
$>=80$ & $(33 \%)$ \\
Sex & \\
Male & 114 \\
Female & $(55 \%)$ \\
& 93 \\
ASA Grade & $(45 \%)$ \\
1 & \\
2 & $12(6 \%)$ \\
3 & 122 \\
4 & $(59 \%)$ \\
Unknown & 64 \\
\hline
\end{tabular}

whether the patient received neoadjuvant or adjuvant therapy between the two groups.

Conclusions Patients in our local population are known to have far greater life expectancy and associated quality of life compared to the rest of the country. Older patients selected for surveillance have certain favourable prognostic factors and better survival. The detection of significant pathology in older adults considered fit for endoscopy supports ongoing surveillance in this group and should be considered on an individual basis for the older population in our area.

\section{PTU-38 MISSED UPPER GASTROINTESTINAL CANCERS: PREDISPOSING FACTORS IN A DISTRICT GENERAL HOSPITAL POPULATION OVER 7 YEARS}

Craig Jordan Tilley*, Arash Vaziri, Anna Cavazza, Roderick Rawiradiradja, Evangelos Chalatsis, Julie Deacon, James Evans, Danielle Morris. East And North Hertfordshire Nhs Trust, Hertford, UK

\subsection{6/gutjnl-2021-BSG.111}

Introduction Missed upper gastrointestinal (GI) cancers are associated with poorer survival outcomes. Missed cancer is defined as having had a negative upper GI endoscopy within three years of confirmatory diagnosis. The aims of this study are to quantify cases of missed upper GI cancer at endoscopy from a district general hospital and identify potential predisposing factors to improve future outcomes.

Methods In this project, retrospective patient records were obtained from MDT meetings run between 2019 and 2020. For data comparison, similar records from previous cohorts were reviewed. The endoscopy records of these patients were extracted from the CIPTS endoscopy recording system and analysed to see if any patient had an endoscopy within the three years prior to diagnosis of their upper GI cancer. Previous endoscopies were scrutinised for the following factors: indication, visible abnormality, biopsy, endoscopist grade, sedation, presentation type, histology and follow up.

\begin{tabular}{llllll} 
Abstract PTU-38 Table 1 & & & \\
\hline Year & $2013-$ & $2014-$ & $2016-$ & $2019-$ & Total \\
& 14 & 15 & 17 & 20 & \\
\hline Missed & 6 & 5 & 4 & 5 & 20 \\
$\begin{array}{l}\text { cancers } \\
\text { Total cancers }\end{array}$ & 65 & 71 & 66 & 78 & 280 \\
Percentage & $9.2 \%$ & $7.0 \%$ & $6.1 \%$ & $6.4 \%$ & $7.1 \%$ \\
\hline
\end{tabular}

Results Of the 280 patients in total, 20 (7.1\%) had a negative endoscopy in three years prior to diagnosis. Subgroup analysis of 2019-20 patients showed identified 78 cases of upper GI cancer. We identified five formal cases of missed upper GI cancer in this subgroup. In the 2019-20 cohort the average age in the missed cancer group and non-missed cancer group were 83.8 and 73.2 years, respectively. Factors identified in missed cancer groups from earlier cohorts included emergency bleeding, visible abnormality not biopsied, administrative delay in rescope and lack of recognition of pathology.

Conclusions The incidence of missed upper GI cancer diagnosis within this centre is similar to that of recent studies from other centres. Our study has highlighted that advanced age, accurate recognition and biopsy, and timely re-biopsy may be factors influencing missed upper GI cancers. This evidence has highlighted the importance of endoscopy training in the recognition and biopsy of pre neoplastic lesions. Furthermore, we intend to analyse data for the year 2020-21 to monitor the impact of COVID-19 on missed upper GI cancer diagnosis.

\section{PTU-39 OUTCOMES OF URGENT ENDOSCOPY DELAYS DURING UK-WIDE LOCKDOWN AT A TEACHING HOSPITAL}

Andrew Baxter, Andrew Baxter*, Stephen Hearing. Royal Derby Hospital, Derby, UK

\subsection{6/gutjnl-2021-BSG.112}

Introduction The COVID-19 pandemic had far reaching consequences for patients beyond those who suffered with the disease. The British Society of Gastroenterology (BSG) advised cessation of all non-emergency endoscopy on 25/03/2020 [1]. A 2 month delay in diagnostics was modelled to result in between $6.4-12.5 \%$ reduction in 10 year survival depending on age and gastrointestinal cancer site [2]. Real world endoscopy data suggests that $37.1 \%, 52.3 \%$ and $72 \%$ of oesophageal, gastric and colorectal cancers, respectively, were not diagnosed in comparison to historical data [3]. However, the true data is currently unknown as patients may have received diagnosis through alternative means such as imaging studies. As we come out of restrictive measures, we will need to answer what happened to these patients, whose diagnoses may have been delayed.

All endoscopy referrals in our centre were vetted by senior clinicians and were streamlined into pathways such as telephone clinics, referral for imaging or deferred until endoscopy services resumed. This abstract analyses the consequences of the emergency measures taken and the impact on our patient cohort.

Methods Patients on either an upper GI or Colorectal two week wait pathway (2WW), were identified prospectively throughout the period of emergency throughout 26/3-4/5/2020 


\begin{tabular}{llll} 
Abstract PTU-39 Table 1 & & & \\
\hline Findings at Endoscopy & 2WW & Urgent & Total \\
\hline Normal & 35 & 20 & 55 \\
Benign pathology & 92 & 26 & 118 \\
$\begin{array}{l}\text { Inflammatory pathology e.g. IBD } \\
\text { Low risk pre-malignant (e.g. low risk }\end{array}$ & 5 & 6 & 11 \\
polyps) & 25 & 12 & 37 \\
High risk pre-malignant (e.g. advanced & 8 & 6 & \\
polyps) & & & 14 \\
Localised malignancy & 18 & 8 & 26 \\
$\begin{array}{l}\text { Disseminated malignancy } \\
\text { Incomplete examination }\end{array}$ & 7 & 0 & 7 \\
\hline
\end{tabular}

[1]. The data were collected and analysed in May 2021 using Microsoft Excel.

Results 108 patients were already on $2 \mathrm{WW}$ at the start of this period and 204 patients were referred for $2 \mathrm{WW}$ endoscopy during this period. 119 patients were referred on an urgent pathway. Nearly a quarter of both groups did not have the procedure they were referred for $(72 / 312$ 2WW, 28/108 Urgent). 1 patient on the $2 \mathrm{WW}$ pathway cancelled their procedure and was later found to have cancer. The mean and median wait times were 80 and 71 days, respectively.

Conclusions We detected cancers in $8 \%$ of the referrals, which is higher than historical national rates of between $3.1-4.1 \%$ [4]. This supports the conclusions from Rutter et al that patients did not seek diagnostic services during this time period [3]. Most of our patients were waiting nearly 3 months for their procedure. It is unclear what impact this will have for their further management, at this time. This period will likely be examined in the years to come to assess for the ultimate cost that patients may have borne as a result of the COVID-19 pandemic.

\section{PTU-40 SURVEILLANCE ENDOSCOPY IN ELDERLY PATIENTS: AN AVENUE FOR COST-SAVING AND REDUCING SERVICE BURDEN}

Shi Jie Looi*, Debabrata Majumdar. Ashford and St. Peter's Hospitals NHS Foundation Trust, Chertsey, UK

\subsection{6/gutjnl-2021-BSG.113}

Introduction In recent years, there has been increasing strain on endoscopy services with increasing activity and consequently, fewer services being able to meet waiting time targets ${ }^{1}$. Disruption to services during the COVID-19 pandemic have also led to a significant increase in the backlog of patients, further exacerbating the problem ${ }^{2}$. We attempt to reduce the burden of this issue at our organisation by reviewing the indication for surveillance of elderly patients against existing national guidelines $3,4,5$.

Methods The list of patients due for surveillance endoscopy was obtained from the endoscopy department database. Inclusion criteria was simply age equal to 80 or above. One author scrutinised electronic case records, reviewing previous endoscopy reports and clinic letters to determine the indication for surveillance. If this was not consistent with national guidelines $3,4,5$, the procedure would be cancelled after discussion and with patient consent.
Results The most common indication for surveillance gastroscopy and colonoscopy was Barrett's oesophagus (89\%) and previous polypectomy (70\%) respectively. From 168 patients reviewed, 75 colonoscopies, 1 flexible sigmoidoscopy and 1 gastroscopy were cancelled. This translates to a cost saving of between $£ 35159$ - $£ 44$ 461. The most common reasons for removal from surveillance were: indication not in keeping with current guidelines (90\%), patient preference (4\%) and frailty (4\%).

Conclusions Our study highlights an easily transferable model to achieve cost savings and reduce unnecessary surveillance endoscopy whilst ensuring quality is maintained by adhering to current national guidelines. These savings could then be utilised to increase service capacity in order to help address the problem of increasing burden on endoscopy services.

\section{REFERENCES}

1. Ravindran $S$, Bassett $P$, Shaw $T$, et al. National census of UK endoscopy services in 2019. Frontline Gastroenterology Published Online First: 24 June 2020. doi:10.1136/flgastro-2020-101538

2. Rutter MD, Brookes M, Lee TJ, et al. Impact of the COVID-19 pandemic on UK endoscopic activity and cancer detection: a National Endoscopy Database Analysis. Gut 2021;70:537-543.

3. Rutter MD, East J, Rees CJ, et al. British Society of Gastroenterology/Association of Coloproctology of Great Britain and Ireland/Public Health England post-polypectomy and post-colorectal cancer resection surveillance guidelines. Gut 2020;69:201-223.

4. Fitzgerald RC, di Pietro M, Ragunath K, et al. British Society of Gastroenterology guidelines on the diagnosis and management of Barrett's oesophagus. Gut 2014;63:7-42

5. Cairns SR, Scholefield JH, Steele RJ, et al. Guidelines for colorectal cancer screening and surveillance in moderate and high risk groups (update from 2002). Gut 2010;59:666-689

\section{PTU-41 MAINTAINING ERCP CAPACITY AND HIGH QUALITY KEY PERFORMANCE QUALITY INDICATORS DURING THE CHALLENGE OF COVID-19}

Ioannis Varbobitis*, Lewis Bulman, Dileep Lobo, Glen Irving, Steve Ryder, Guru Aithal, Suresh Venkatachalapathy, Adolfo Parra-Blanco, Martin James. NIHR Nottingham Biomedical Research Centre, Nottingham University Hospitals NHS Trust and the University of Nottingham, Nottingham, UK

\subsection{6/gutjnl-2021-BSG.114}

Introduction COVID-19 has negatively impacted on the delivery of endoscopy services worldwide. In the UK, national endoscopy database (NED) indicated activity was dramatically reduced by $80-95 \%$ during the first wave in 2020, due to redeployment of staff, challenges with personal protective equipment (PPE), room air-change cycle and patients' unwillingness to attend during lockdown restrictions. ERCP is a higher-risk procedure often performed in patients with an urgent indication such as cancer obstruction or gallstonerelated biliary sepsis or pancreatitis. We aimed to define the impact of COVID-19 on our ERCP service delivery, clinical outcomes, patient safety and endoscopists' KPIs.

Methods We examined Nottingham ERCP outcomes during the COVID-19 pandemic in 2020 compared to those before in 2019 at a high-volume HPB endoscopy centre serving a local population of 750,000 and tertiary HPB MDT population of 2.3 million. Technical success, comfort rates and complications according to RCP JAG and ESGE quality standards, including 8- and 30-day readmission rates and deaths were recorded. We also assessed the incidence of Covid-19 infection among the population who underwent ERCP. 